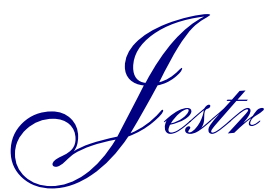

\title{
Experimental Study on the Static and Dynamic Mechanical Properties of Coal under Different Gas Pressures
}

\author{
Yin Zhiqiang ${ }^{1,2, *}$, Zhang Zhuo $^{1}$, Ma Haifeng ${ }^{1}$, Hu Zuxiang ${ }^{1}$ and Tang Mingyun ${ }^{1}$ \\ ${ }^{1}$ School of Mining and Safety, Anhui University of Science and Technology, Huainan 232001, China \\ ${ }^{2}$ Centre for Infrastructural Monitoring and Protection, School of Civil and Mechanical Engineering, Curtin University, WA 6102, \\ Australia
}

Received 8 April 2018; Accepted 17 September 2018

\begin{abstract}
In deep coal mines, a coal seam usually contains high gas pressure and is subjected to static and dynamic loading due to mining-induced stress and sudden fracture of hard roof. In this study, two experimental equipment of gas-containing coal under static and dynamic loading was developed for the investigation of the static and dynamic mechanical properties of coal under various gas pressures. The first one was gas-solid coupling equipment with quasi-static loading developed on the basis of the RMT-150 testing machine. The other one was coupled gas-dynamic loading equipment modified from a split Hopkinson pressure bar. By using the modified equipment, the static and dynamic compressive strengths of coal were tested under four gas pressures, namely, 0, 0.5, 1.0, and $1.5 \mathrm{MPa}$, respectively. Results show that gas pressure clearly affects the stress-strain curve and strength of coal. As the initial gas pressure increases from $0 \mathrm{MPa}$ to $1.5 \mathrm{MPa}$, the static strength decreases from $23.95 \mathrm{MPa}$ to $13.28 \mathrm{MPa}$, and the dynamic strength also decreases from $41.78 \mathrm{MPa}$ to 32.21 MPa. The failure strain of the specimen decreases from 0.90 to 0.51 under the static loading and increases from 0.56 to 0.74 under the dynamic loading. Meanwhile, the average dynamic increase factor (DIF) of compressive strength increases from 1.78 to 2.34 as the initial gas pressure increases. However, the gas influence factor (GIF) of compressive strength decreases from 1.00 to 0.77 . The phenomena suggest that the mechanical property of coal under static loading is more sensitive to gas pressure than under dynamic loading, indicating the prominent influence of the loading mode on the failure mode of gas-containing coal. Hence, the results can provide an experimental basis for studies of the mechanisms of coal and gas outburst in deep coal mines.
\end{abstract}

Keywords: Gas-containing coal, Coupled loadings, Dynamic strength, DIF, Split Hopkinson pressure bar

\section{Introduction}

In eastern China, coal mines are constantly moving deeper owing to the gradual depletion of coal resources in shallow areas. For instance, in the Huainan Mining Area, the average depth of the working face is up to $800 \mathrm{~m}$ below the ground surface, and the mining depth increases by 12-25 m annually. Deep coal seams are typically characterized by high gas pressure (with methane being the main gas) and low permeability. As mining activities continue to increase in deeper areas, mining-induced stress and gas pressure of the coal seam in front of the working face constant increase. Consequently, the hidden danger of dynamic disasters, such as coal and gas outburst in the deep coal seam, becomes prominent [1]. The mechanism of these dynamic disasters has attracted the attention of researchers devoted to coal mine engineering and rock mechanics. Previous studies on coal and gas outburst disasters were focused on the expansion effect of gas pressure in coal. Research suggests that gas expansion energy is released rapidly, and then coal and gas outburst accidents occur when the gas expansion energy stored in the coal seam exceeds the strength of coal near the working face. Hence, the instability [2] and energy

\footnotetext{
*E-mail address: zhqyin@aust.edu.cn

ISSN: 1791-2377 @ 2018 Eastern Macedonia and Thrace Institute of Technology. All rights reserved. doi:10.25103/jestr.114.08
}

[3] models of coal and gas outburst were proposed. In deep mining, mining-induced stress of coal seam considerably increases. On the one hand, stress evidently concentrates in the coal in front of the working face, thus imposing a high static stress load on the coal. The coal in the stress concentration area is in the typical coupling of static stress and gas pressure. On the other hand, during deep coal seam mining, given the unusual conditions such as multiple hard rock layers above the coal seam and intensive mining by using large-scale comprehensive mechanized equipment, hard roof fracture leads to a robust stress wave disturbance phenomenon, imposing apparent dynamic loading to the coal $[4,5]$. Thus, the coal seam in front of the working face of deep gas-containing coal mine is subjected to increasingly complex stresses typically characterized by coupled gas pressure, static loading, and dynamic loading. This complex state of coupled stresses will affect the mechanism of coal and gas outburst dynamic disasters in coal mines. Therefore, investigating the mechanical properties of deep gascontaining coal seam under different loading conditions has great practical importance.

In this study, the mechanical properties of gas-containing coal under static and dynamic loading were comparatively analyzed, and then the failure models of gas-containing coal with different loading methods were established. The research results can provide an experimental basis for the 
investigation on the mechanism of coal and gas outburst in deep coal mines.

\section{State of the art}

Unlike other rocks, such as sandstone and granite, gascontaining coal should maintain the state of gas occurrence in a mechanical test. In the last several decades, appropriate test equipment has been developed and improved, and experimental studies were conducted on the uniaxial and triaxial compression mechanical properties of gas-containing coal under static loads $[6,7]$. He et al. [8] examined the gas state of gas-containing coal during external stress loading, and they found that large amounts of adsorbed gas were released and desorbed when gas-containing coal is damaged. Ranjith et al. [9] measured the uniaxial compressive strength (UCS) of an Australian black coal and obtained a decrease in UCS with increasing gas (CO2) pressure. Xie et al. [10] investigated the strength characteristics of gas-containing coal by using self-developed gas-solid coupling equipment. The results demonstrate that an increased gas pressure leads to reductions in the UCS of gas-containing coal and critical dilatancy stress, thereby promoting the development of fractures. Xu et al. [11] evaluated the shear characteristics of gas-containing coal and concluded that gas can promote the shear strength of coal, resulting in the generation and expansion of additional cracks. After studying the fracture toughness of gas-containing coal by using notched semicircular bending specimens, Yin et al. [12] revealed that the increase of gas pressure reduced the fracture toughness and raised the speed of crack propagation. In these experiments, the gas state of deep gas-containing coal seam was effectively simulated via a gas-sealing device, and the test results can accurately reflect the mechanical properties of gas-containing coal under static load. Nevertheless, the static loads applied in these experiments were slightly different from the actual stress load state of deep coal mining, which is also subjected to dynamic loads. Therefore, comparatively analyzing the mechanical properties of gas-containing coal under static and dynamic loading is necessary after evaluating the properties under dynamic loading. The study has some engineering importance in understanding the mechanism of coal and gas outburst in deep coal mines.

Presently, the split Hopkinson pressure bar (SHPB), which is recommended by the International Society for Rock Mechanics, has been extensively used to measure the dynamic mechanical characteristic of rock materials. Shan et al. [13] evaluated the dynamic mechanical properties of anthracite samples in different loading rates by using the SHPB and established the dynamic constitutive models. Zhao et al. [14] examined the dynamic tensile strength of coal under dry and saturated conditions. The results show that the dynamic tensile coal exhibits a typical strain rate effect which is considerable when the coal is saturated. In the previously mentioned experiments, the dynamic load of deep gas-containing coal seam was effectively simulated via the SHPB experiment. However, a large volume of gas is present in the coal seam during the coal mining; thus, the gas state will affect in the dynamic mechanical experiment. In recent years, traditional SHPB experiment equipment has been modified by many researchers to simulate the coupled stress state characteristics in the field of deep engineering $[15,16]$. To simulate the state of coupled static and dynamic loading in deep mines, Li et al. [17] developed a coupled static and dynamic loading experiment equipment based on the SHPB. The researchers used the equipment to determine the mechanical properties, such as compressive strength and energy consumption, of sandstone under a coupled loading. To simulate the high-temperature environment in deep rock, Yin et al. [18] developed the coupled temperature and dynamic loading experiment equipment. By using the equipment, the researchers investigated the mechanical properties of granite under coupled heat and dynamic loading. These studies suggested that the coupled state of deep engineering can be simulated using the modified SHPB Although these experiments are focused on rock materials, they provided an excellent idea for the investigation of dynamic mechanical properties of gas-containing coal by using the research methods of modified SHPB. Therefore, traditional SHPB equipment modified with reference to the gas-sealing device in the static loading experiment can simulate the coupled gas and dynamic loading in the deep gas-containing coal seam.

Given the limitations of existing studies, a novel dynamic experimental system of gas-containing coal was developed in this study. A gas-sealing device was added on the traditional SHPB to ensure stable gas pressure during the dynamic loading experiment. Furthermore, the modified equipment was used to investigate the dynamic and static mechanical properties of coal under various gas pressures. The influencing factors of mechanical properties of gascontaining coal under different loading modes were analyzed by comparing the experimental results, and then the failure model of gas-containing coal under static and dynamic loading was established. The research results can provide an empirical basis for the investigation on the mechanism of coal and gas outburst in deep coal mines.

The rest of this study is organized as follows. The static and dynamic loading test equipment of gas-containing coal, method of sample preparation, and necessary parameters are introduced in Section 3. The influence of different loading modes on the failure process of gas-containing coal is investigated in Section 4 by analyzing the gas influence factor (GIF) of dynamic strength and dynamic increase factor (DIF). Finally, conclusions are presented in Section 5.

\section{Methodology}

\subsection{Specimen preparation}

The coal samples used in this study were collected from Xieqiao Coal Mine in Huainan Mining Area, China. This coal seam is a typical high-gas, low-permeability coal seam. The adsorption constants of the coal are $35.428 \mathrm{~m}^{3} / \mathrm{t}$ and $1.163 \mathrm{MPa}^{-1}$ at room temperature $\left(26^{\circ} \mathrm{C}\right)$. The samples collected on site were covered with wrapping polythene to prevent loss of original moisture content. All the samples were cut and ground under atmospheric conditions. The quasi-static and dynamic tests were simultaneously performed on the prism and cylindrical samples whose ends and sides had been carefully polished. The thresholds were set to smaller than $0.02 \mathrm{~mm}$ to ensure parallelism and perpendicularity [19]. The samples were gray and smooth without any distinct interspace on the surface, as shown in Fig. 1. In this study, the specimens that did not absorb gas were selected for the controlled tests, and four specimens were selected to determine the mechanical parameters of raw coal. By using the gas-sealing device, four specimens were tested in each initial gas pressure (i.e., 0.5, 1.0, and 1.5 MPa) at room temperature for $24 \mathrm{~h}$. 
Yin Zhiqiang, Zhang Zhuo, Ma Haifeng, Hu Zuxiang and Tang Mingyun/

Journal of Engineering Science and Technology Review 11 (4) (2018) 61 - 68

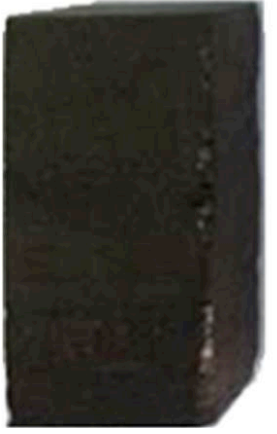

(a)

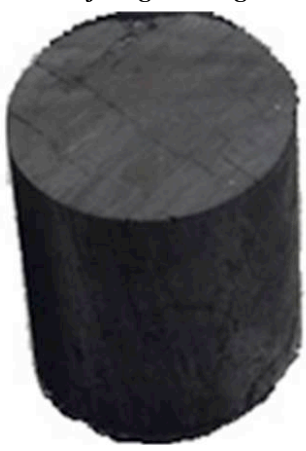

(b)
Fig. 1. Testing specimens. (a) Specimens for the quasi-static tests, $50 \times$ $25 \times 25 \mathrm{~mm}$. (b) Specimens for the dynamic tests, $50 \times 50 \mathrm{~mm}$

\subsection{Quasi-static loading tests}

The quasi-static compressive tests were conducted using the self-developed equipment for visual gas-solid coupling mechanics and the RMT-150 hydraulic servo-control testing machine at the mining laboratory of Anhui University of Science and Technology (China), as shown in Fig. 2. The specimens under compressive load are illustrated in Figure 1 (a). Variations of vertical load and displacement of the specimen with time were recorded via the RMT measurement software. Notably, grease was applied to the interface between the specimen and the apparatus for the quasi-static compressive tests to minimize end friction.

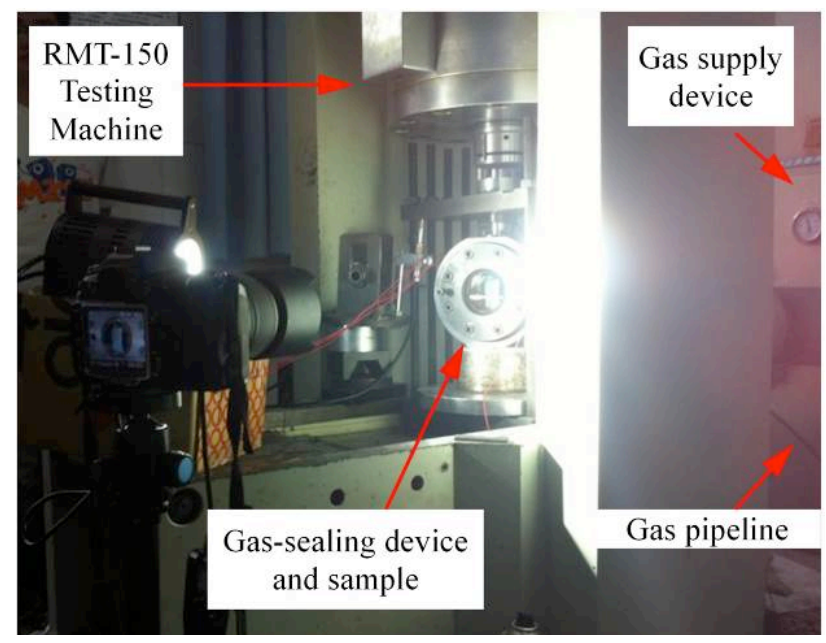

Fig. 2. Experimental system of gas-containing coal under quasi-static loads

\subsection{Coupled gas-dynamic loading equipment}

In previous studies, dynamic mechanical properties of rocks under coupled static and dynamic stress conditions were investigated using the modified SHPB equipment [20, 21]. In this study, a novel experimental system (Fig. 3), in which the gas-containing coal specimen can be tested under dynamic and static loading, was developed in Anhui University of Science and Technology. This dynamic system consists of a stress wave generator (air gun), a stress transfer device (incident and transmission bars), an axial static pressure-loading device, a test data recording device, and a gas pressure control device, among which the first four devices are the same as that of the coupled static-dynamic loading equipment. During the dynamic loading test, the gas pressure control device is responsible for maintaining the gas pressure.

As shown in Fig. 4, the gas pressure control equipment includes gas-sealing and gas supply devices. The gas-sealing device can open two connecting holes in the horizontal direction with coaxial pressure bar. That is, the incident and transmission bars can be sent into the gas-sealing device (Fig. 3(b)). An O-shaped ring and two Y- and X-shaped sealing rings were arranged between the gas-sealing device and pressure bar to seal the gas. This device was connected to the gas supply device through a gas pipeline to ensure that gas pressure in the sample remains in a stable environment.

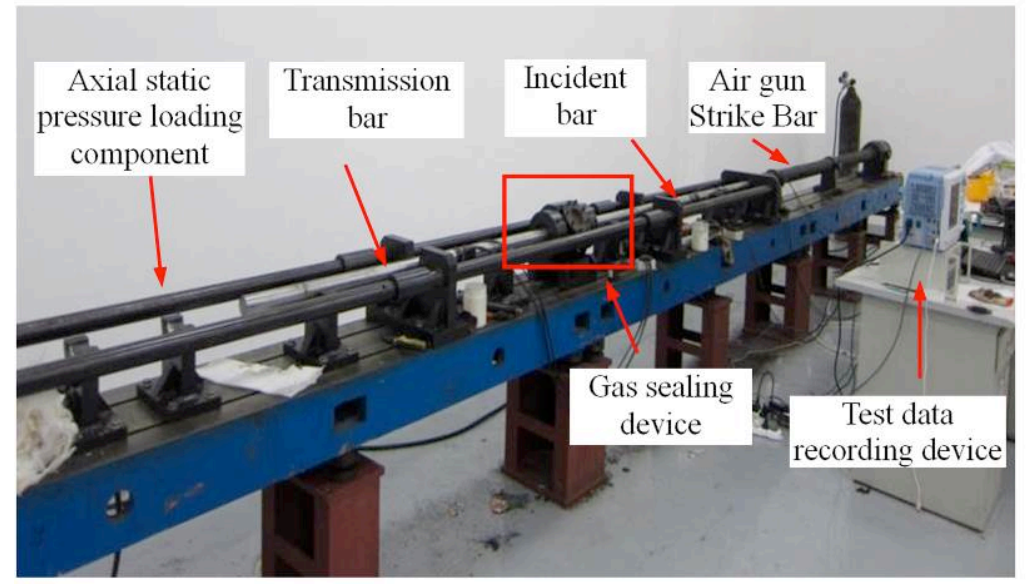

(a)

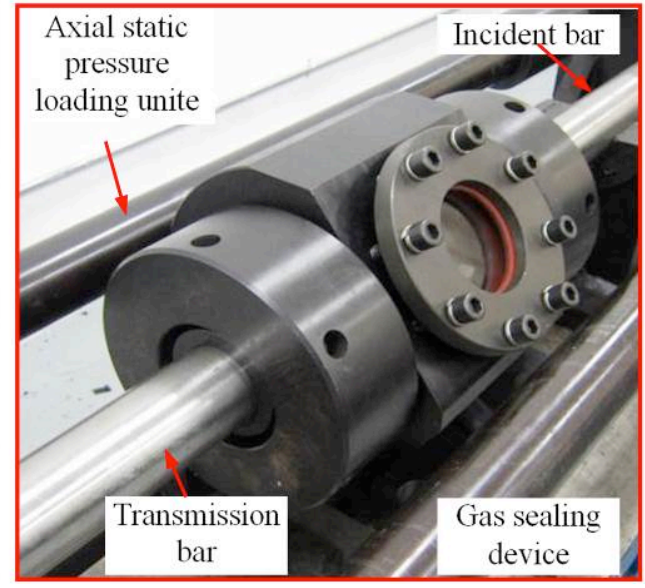

(b)

Fig. 3. Experimental system of coupled gas static-dynamic loads. (a) Dynamic loading equipment. (b) Gas-sealing device 


\section{Result analysis and discussion}

\subsection{Results of quasi-static tests}

The typical stress-strain curves of gas-containing coal specimens obtained from quasi-static compressive tests are presented in Fig. 5. As shown in the figure, the compressive strength $\left(\sigma_{\mathrm{s}}\right)$ and static failure strain $\left(\varepsilon_{\mathrm{ps}}\right)$ remarkably decrease when the gas pressure increases from $0 \mathrm{MPa}$ to 1.5 $\mathrm{MPa}$. All the test results of the quasi-static specimens with different initial gas pressures in this study are summarized in Table 1. As presented in Table 1 and Fig. 5, the initial gas pressure affects the static compressive strength and static failure strain of the coal specimen. As the initial gas pressure increases from $0 \mathrm{MPa}$ to $1.5 \mathrm{MPa}$, the average static strength decreases gradually from $23.95 \mathrm{MPa}$ to $13.28 \mathrm{MPa}$, and the average static failure strain also decreases gradually from 0.0090 to 0.0051 , as presented in Table 1 .

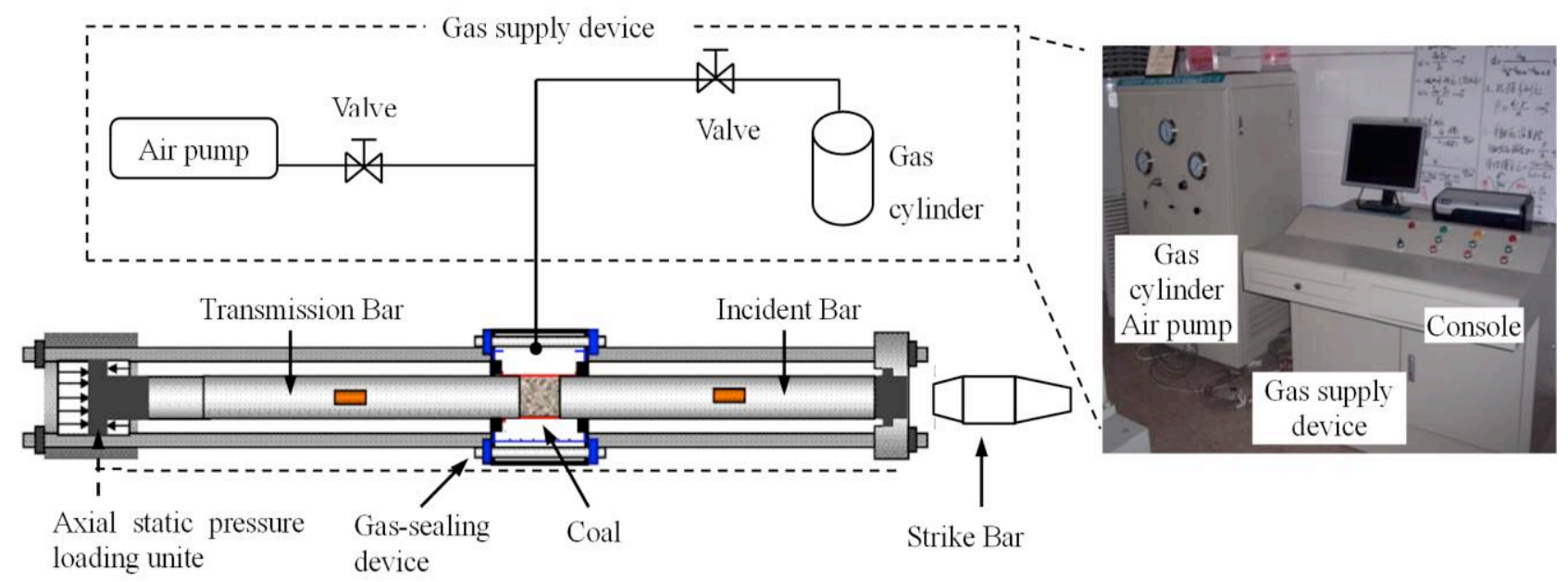

Fig. 4. Schematic of gas state device

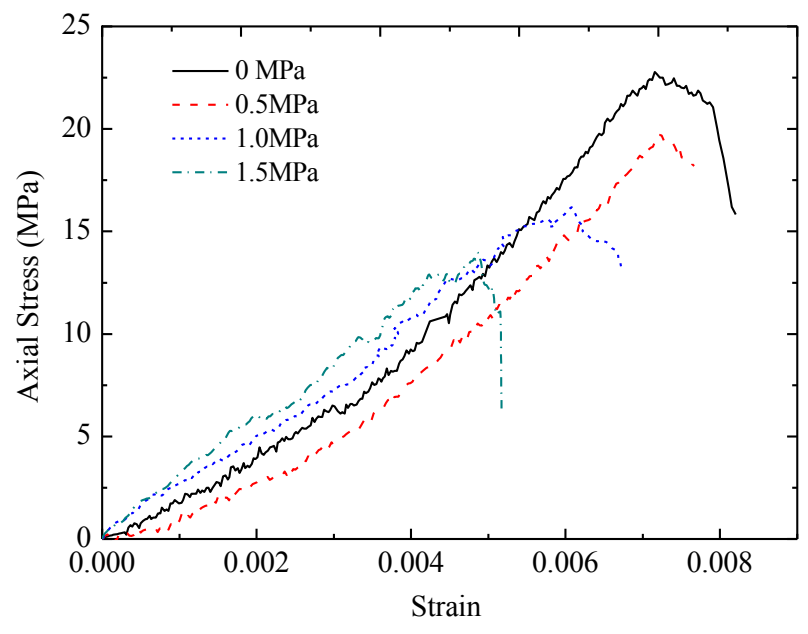

Fig. 5. Stress-strain curves of coal with different gas pressures from quasi-static compressive tests

\subsection{Results of the dynamic tests}

The one-dimensional stress wave theory was applied to samples under coupled gas pressure and dynamic loading. The dynamic compressive stress $\left(\sigma_{\mathrm{d}}\right)$ and dynamic strain $\left(\varepsilon_{\mathrm{d}}\right)$ were calculated in light of the theory during the experiment by using the following formulas [22].

$$
\begin{aligned}
& \sigma(t)=\frac{A_{\mathrm{e}}}{A_{\mathrm{s}}} E_{\mathrm{e}} \varepsilon_{t}(t) \\
& \varepsilon(t)=-\frac{2 c_{\mathrm{e}}}{L_{\mathrm{S}}} \int_{0}^{t} \varepsilon_{\mathrm{r}}\left(t^{\prime}\right) \mathrm{d} t^{\prime}
\end{aligned}
$$

$$
\dot{\varepsilon}(t)=-\frac{2 c_{\mathrm{e}}}{L_{\mathrm{S}}} \varepsilon_{\mathrm{r}}(t)
$$

where $C_{\mathrm{e}}$ is the wave velocity of elastic bar, $L_{\mathrm{S}}$ is the sample length, $\varepsilon_{\mathrm{r}}(t)$ is the strain of reflected stress wave at time $t, A_{\mathrm{e}}$ is the cross-sectional area of the elastic bar, $A_{\mathrm{s}}$ is the cross-sectional area of the specimen, $E_{\mathrm{e}}$ is the elastic modulus of the elastic bar, and $\varepsilon_{\mathrm{t}}(t)$ is the strain of the transmitted stress wave at time $t$.

The results of signals obtained from the typical dynamic loading test of gas-containing coal specimens, which have a similar striking velocity of approximately $9 \mathrm{~m} / \mathrm{s}$, are exhibited in Fig. 6. Meanwhile, the stress variations of the sample incident and transmission terminal under dynamic loading are illustrated in Fig. 7. The time of stress equilibrium before the fracture is approximately $110 \mu \mathrm{s}$ (Fig. 7). Hence, the stress equilibrium state of the specimen should be regarded as a prerequisite for dynamic fracture toughness determination of the quasi-static theory to obtain satisfactory results. The typical stress-strain curves of coal specimens with various gas pressures are shown in Fig. 8. All the dynamically tested samples with different initial gas pressures in this study are summarized in Table 1. As shown in Table 1 and Fig. 8, the initial gas pressure affects the dynamic compressive strength and dynamic failure strain of the specimen. As the initial gas pressure increases from 0 $\mathrm{MPa}$ to $1.5 \mathrm{MPa}$, the average dynamic strength $\left(\sigma_{\mathrm{d}}\right)$ decreases gradually from $41.78 \mathrm{MPa}$ to $32.21 \mathrm{MPa}$. However, the average dynamic failure strain $\left(\varepsilon_{\mathrm{pd}}\right)$ increases continuously from 0.0056 to 0.0074 , as presented in Table 1 . This result demonstrates that under dynamic loading conditions, the plastic part of gas-containing coal increases with the increase of gas pressure. As the gas pressure 
increases, the static and dynamic strengths decrease However, the dynamic failure strain stops decreasing and starts increasing when the load shifts from static to dynamic. These results show that the loading mode can exert different effects on the failure of gas-containing coal. With equal gas pressure, the gas-containing coal under static loading is compared with dynamic loading in this study. With an initial gas pressure of $1.5 \mathrm{MPa}$, the coal strength increases from 15.24 MPa to $32.21 \mathrm{MPa}$. Generally, the strain rate increases from $10^{-4}$ to $10^{2}$, when the load shifts from static to dynamic. This result demonstrates that a coal is a material exhibiting a typical strain rate effect.

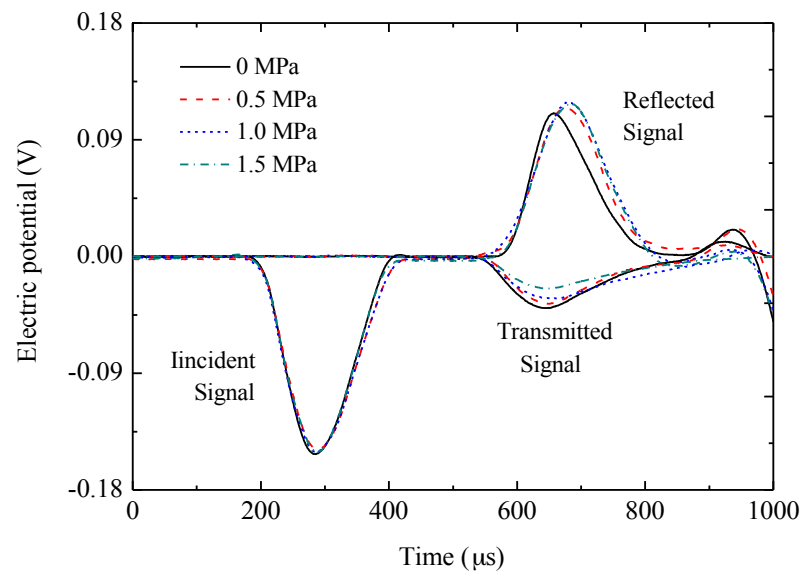

Fig. 6. Raw signals of a typical dynamic loading test of gas-containing coal

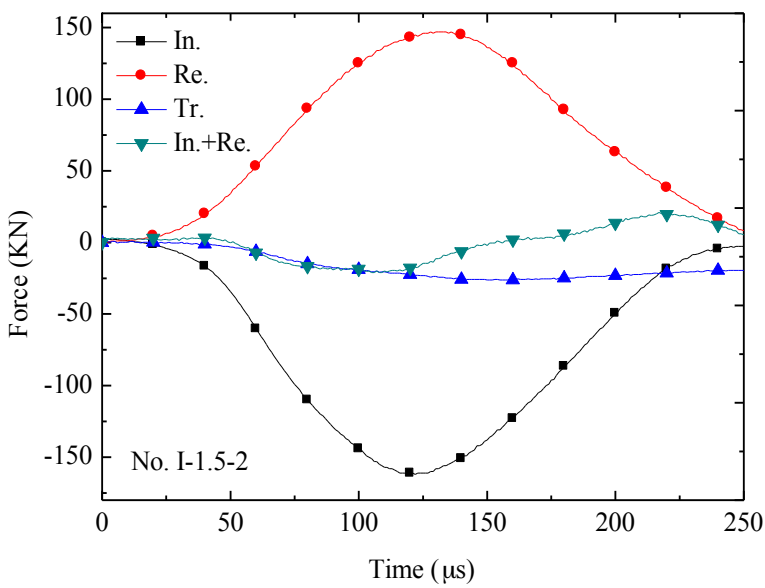

Fig. 7. Balance check of dynamic stress for dynamic loading

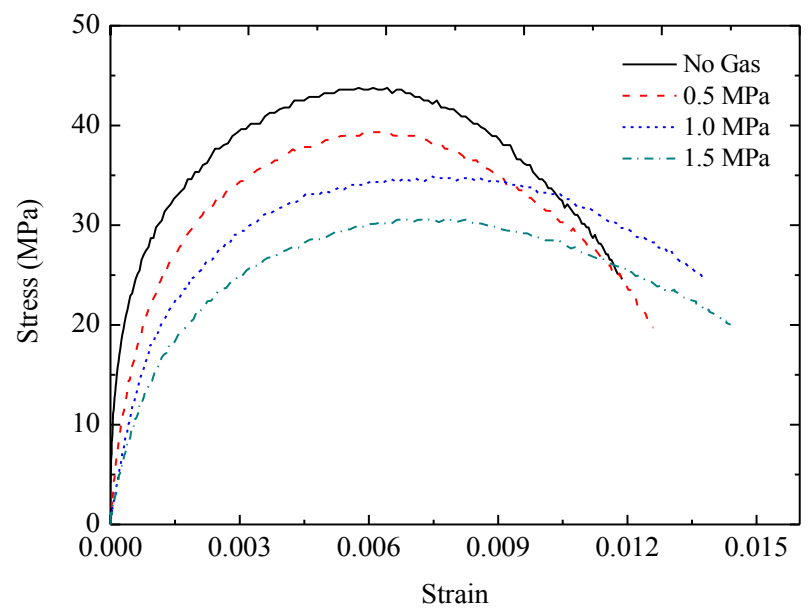

Fig. 8. Stress-strain curves of coal with different gas pressures from dynamic tests
4.3 Influence factor of the strength of gas-containing coal In previous studies, the dynamic strength $\left(\sigma_{\mathrm{d}}\right)$ is usually higher than the quasi-static strength $\left(\sigma_{\mathrm{s}}\right)$ due to the strain rate effect. The DIF of the compressive strength is defined as follows [23]:

$$
\mathrm{DIF}=\frac{\sigma_{\mathrm{d}}}{\sigma_{\mathrm{s}}}
$$

The results of this study suggested that the gas adsorption state of coal caused the reduction of its dynamic strength. Hence, the GIF of the dynamic strength, which can reflect the influence of gas on the dynamic compressive strength of coal, is defined as follows:

$$
\mathrm{GIF}=\frac{\sigma_{\mathrm{dg}}}{\sigma_{\mathrm{dn}}}
$$

where $\sigma_{\mathrm{dg}}$ is the dynamic compressive strength of coal with different gas pressures and $\sigma_{\mathrm{dn}}$ is the dynamic compressive strength of a coal with no gas.

The DIF and GIF results from the dynamic tests of gascontaining coal with different initial gas pressures are presented in Table 2 . With equal striking velocity, the strain rates of samples with different initial gas pressures are approximately the same, that is, within the range of 105.7$134.7 \mathrm{~s}^{-1}$. With the increase of gas pressure, the strain rate increased slowly due to the increase in the plasticity of coal during its gas adsorption. Moreover, the dynamically tested DIF and GIF are compared under the condition of similar strain rates, as shown in Fig. 9. The variation trends of DIF and GIF are not consistent with that of the gas pressure increase. As the initial gas pressure increased from $0 \mathrm{MPa}$ to $1.5 \mathrm{MPa}$, the average DIF on the compressive strength of gas-containing coal increased from 1.78 to 2.34 , suggesting that the strain rates of gas-containing coal becomes increasingly sensitive in this process. However, the average GIF of gas-containing coal decreased from 1.00 to 0.77 . Hence, unlike the static mechanical properties, the dynamic mechanical properties are less sensitive to the gas pressure due to the effect of the strain rate.

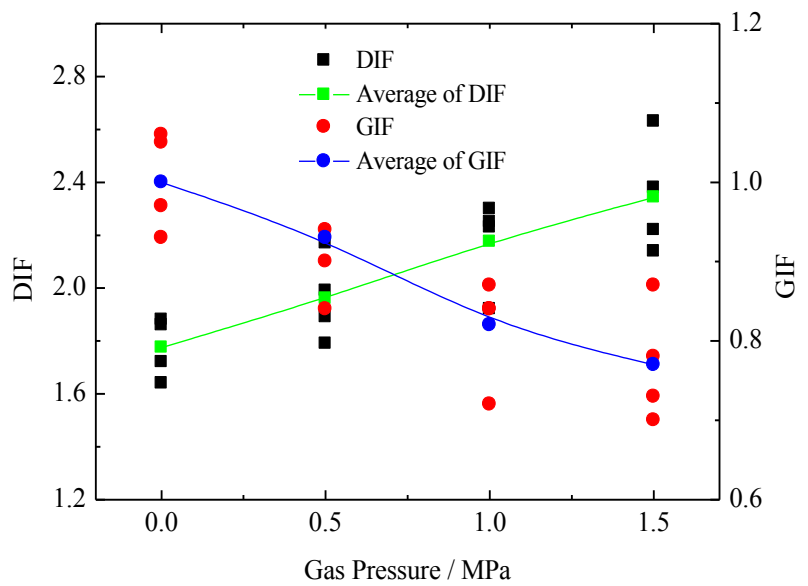

Fig. 9. DIF and GIF of the compressive strength of gas-containing coal with different gas pressures 
Yin Zhiqiang, Zhang Zhuo, Ma Haifeng, Hu Zuxiang and Tang Mingyun/

Table 1. Results of the quasi-static and dynamic compressive tests with various gas pressures

\begin{tabular}{|c|c|c|c|c|c|c|c|c|c|}
\hline \multirow[b]{2}{*}{ Specimen } & \multicolumn{4}{|c|}{ Quasi-static tests } & \multirow[b]{2}{*}{ Specimen } & \multicolumn{4}{|c|}{ Dynamic tests } \\
\hline & $\begin{array}{c}\sigma_{\mathrm{s}} \\
(\mathrm{MPa})\end{array}$ & $\begin{array}{c}\text { Average } \\
\sigma_{\mathrm{s}}\end{array}$ & $\begin{array}{l}\varepsilon_{\mathrm{ps}} \\
(\%)\end{array}$ & $\begin{array}{c}\text { Average } \\
\varepsilon_{\mathrm{ps}}\end{array}$ & & $\begin{array}{c}\sigma_{\mathrm{d}} \\
(\mathrm{MPa})\end{array}$ & $\begin{array}{c}\text { Average } \\
\sigma_{\mathrm{d}}\end{array}$ & $\begin{array}{l}\varepsilon_{\text {pd }} \\
(\%)\end{array}$ & $\begin{array}{c}\text { Average } \\
\varepsilon_{\mathrm{pd}}\end{array}$ \\
\hline \multicolumn{10}{|l|}{ GP $0 \mathrm{MPa}$} \\
\hline S-0-1 & 22.79 & \multirow{4}{*}{23.95} & 0.74 & \multirow{4}{*}{0.90} & $\mathrm{I}-0-1$ & 43.77 & \multirow{4}{*}{41.78} & 0.58 & \multirow{4}{*}{0.56} \\
\hline $\mathrm{S}-0-2$ & 24.66 & & 0.89 & & $\mathrm{I}-0-2$ & 38.71 & & 0.63 & \\
\hline $\mathrm{S}-0-3$ & 20.51 & & 0.71 & & $\mathrm{I}-0-3$ & 40.38 & & 0.53 & \\
\hline S -0-4 & 27.85 & & 1.25 & & $\mathrm{I}-0-4$ & 44.24 & & 0.49 & \\
\hline \multicolumn{10}{|l|}{ GP $0.5 \mathrm{MPa}$} \\
\hline $\mathrm{S}-0.5-1$ & 19.73 & \multirow{4}{*}{20.63} & 0.72 & \multirow{4}{*}{0.73} & $\mathrm{I}-0.5-1$ & 39.33 & \multirow{4}{*}{38.71} & 0.62 & \multirow{4}{*}{0.67} \\
\hline S- $0.5-2$ & 23.20 & & 0.67 & & $\mathrm{I}-0.5-2$ & 42.84 & & 0.57 & \\
\hline S - $0.5-3$ & 20.68 & & 0.91 & & $\mathrm{I}-0.5-3$ & 35.27 & & 0.76 & \\
\hline S - $0.5-4$ & 18.90 & & 0.61 & & $\mathrm{I}-0.5-4$ & 37.39 & & 0.63 & \\
\hline \multicolumn{10}{|l|}{ GP $1.0 \mathrm{MPa}$} \\
\hline S -1.0-1 & 16.12 & \multirow{4}{*}{15.24} & 0.61 & \multirow{4}{*}{0.62} & I-1.0-1 & 34.97 & \multirow{4}{*}{34.17} & 0.74 & \multirow{4}{*}{0.70} \\
\hline S - $1.0-2$ & 12.61 & & 0.54 & & I- $1.0-2$ & 30.21 & & 0.68 & \\
\hline $\mathrm{S}-1.0-3$ & 13.40 & & 0.62 & & I-1.0-3 & 35.29 & & 0.71 & \\
\hline S -1.0-4 & 18.81 & & 0.72 & & I-1.0-4 & 36.21 & & 0.65 & \\
\hline \multicolumn{10}{|l|}{ GP $1.5 \mathrm{MPa}$} \\
\hline $\mathrm{S}-1.5-1$ & 14.04 & \multirow{4}{*}{13.28} & 0.47 & \multirow{4}{*}{0.51} & $\mathrm{I}-1.5-1$ & 30.56 & \multirow{4}{*}{32.21} & 0.75 & \multirow{4}{*}{0.74} \\
\hline $\mathrm{S}-1.5-2$ & 17.80 & & 0.69 & & I-1.5-2 & 32.74 & & 0.73 & \\
\hline $\mathrm{S}-1.5-3$ & 12.26 & & 0.51 & & I-1.5-3 & 36.15 & & 0.64 & \\
\hline S - 1.5-4 & 9.03 & & 0.35 & & I- $1.5-4$ & 29.37 & & 0.82 & \\
\hline
\end{tabular}

Note: GP - initial gas pressure

Table 2. GIF and DIF on compressive strength in dynamic loading

\begin{tabular}{|c|c|c|c|c|c|}
\hline Specimen & Strain rate $\left(\mathrm{s}^{-1}\right)$ & GIF & Average GIF & DIF & Average DIF \\
\hline \multicolumn{6}{|l|}{ GP $0 \mathrm{MPa}$} \\
\hline I-0-1 & 113.5 & 1.05 & \multirow{4}{*}{1.00} & 1.86 & \multirow{4}{*}{1.78} \\
\hline $\mathrm{I}-0-2$ & 110.6 & 0.93 & & 1.64 & \\
\hline $\mathrm{I}-0-3$ & 113.2 & 0.97 & & 1.72 & \\
\hline $\mathrm{I}-0-4$ & 114.8 & 1.06 & & 1.88 & \\
\hline \multicolumn{6}{|l|}{ GP $0.5 \mathrm{MPa}$} \\
\hline $\mathrm{I}-0.5-1$ & 112.6 & 0.94 & \multirow{4}{*}{0.93} & 1.99 & \multirow{4}{*}{1.96} \\
\hline $\mathrm{I}-0.5-2$ & 115.2 & 1.03 & & 2.17 & \\
\hline $\mathrm{I}-0.5-3$ & 113.5 & 0.84 & & 1.79 & \\
\hline I-0.5-4 & 114.4 & 0.90 & & 1.89 & \\
\hline \multicolumn{6}{|l|}{ GP $1.0 \mathrm{MPa}$} \\
\hline I-1.0-1 & 128.3 & 0.84 & \multirow{4}{*}{0.82} & 2.23 & \multirow{4}{*}{2.18} \\
\hline I-1.0-2 & 125.7 & 0.72 & & 1.92 & \\
\hline I-1.0-3 & 127.3 & 0.84 & & 2.25 & \\
\hline I-1.0-4 & 127.2 & 0.87 & & 2.3 & \\
\hline \multicolumn{6}{|l|}{ GP $1.5 \mathrm{MPa}$} \\
\hline I-1.5-1 & 133.3 & 0.73 & \multirow{4}{*}{0.77} & 2.22 & \multirow{4}{*}{2.34} \\
\hline $\mathrm{I}-1.5-2$ & 133.6 & 0.78 & & 2.38 & \\
\hline $\mathrm{I}-1.5-3$ & 134.7 & 0.87 & & 2.63 & \\
\hline I-1.5-4 & 130.8 & 0.70 & & 2.14 & \\
\hline
\end{tabular}

According to Wang et al. [24], the material with high strength has high sensitivity to strain rate under dynamic load. In this study, with the increase of gas pressure, the specimen of gas-containing coal becomes increasingly sensitive to strain rates. However, the dynamic compressive strength of gas-containing coal increased. The mechanical parameters of gas-containing coal are notably affected by gas desorption in the loading process [10]. Therefore, in this study, the results of the strain rate effects might be attributed to the difference in the gas desorption from gas-containing coal obtained by various stress loading methods. Pore deformation and desorption of the adsorbed gas in gascontaining coal under static and dynamic loading conditions are shown in Fig. 10. Generally, the pore of gas-containing coal with static loads takes longer time from deformation to failure. Therefore, the crack tip is expanded by desorption gas for a longer time and more adsorptive gas desorption. The crack propagation and failure are caused by the combination of static load and gas expansion stress. As exhibited by the SHPB test in this study, when subjected to dynamic loads, the specimen only takes a short time (approximately $100 \mu \mathrm{s}$ ) to fail to ensure that the adsorbed gas does not have sufficient time to be fully desorbed and promotes crack propagation. In other words, compared with dynamic loading, static loading results in a higher degree of gas desorption. Therefore, with the increase of gas pressure, the compressive strength decreases more significantly when the coal is subjected to static loading. Generally, the gas desorption has a slight effect on the fracture process of gascontaining coal under high strain rate. Thus, the skeleton structure of coal determined the dynamic strength, in which its decrease is due to the weakening coal formation after gas absorption. Therefore, the value of DIF increased with the rise in gas pressure. The time of dynamic loading is short (in microseconds) in this study, but the time (i.e., blast, mineral earthquake) in the engineering field is long (in seconds) [25] Therefore, further investigating the effects of the loading waveform of dynamic stress waves on pore deformation and gas adsorption state is necessary. 


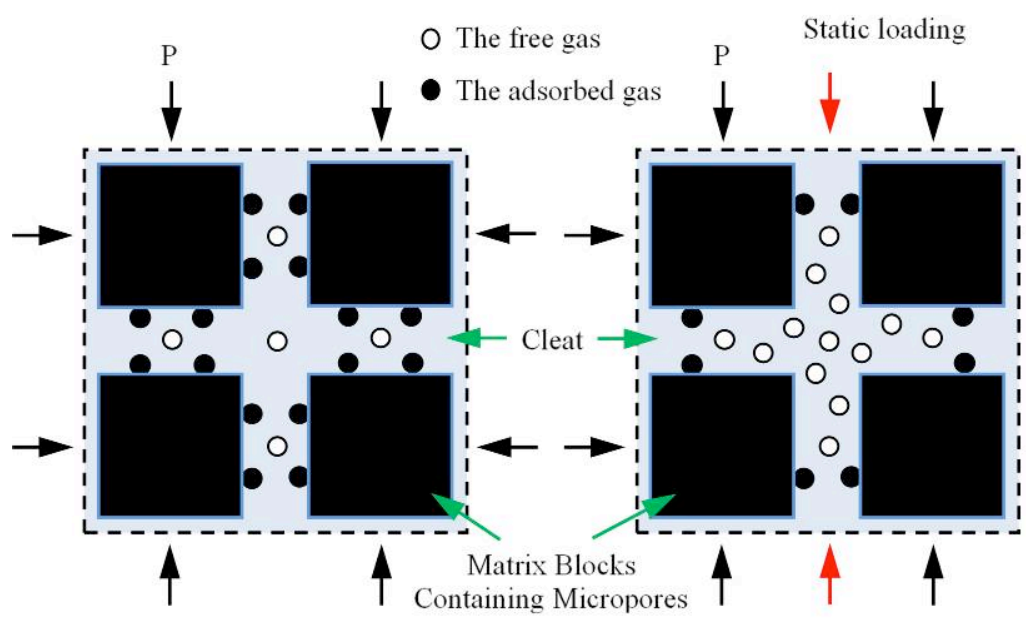

(a) (b)

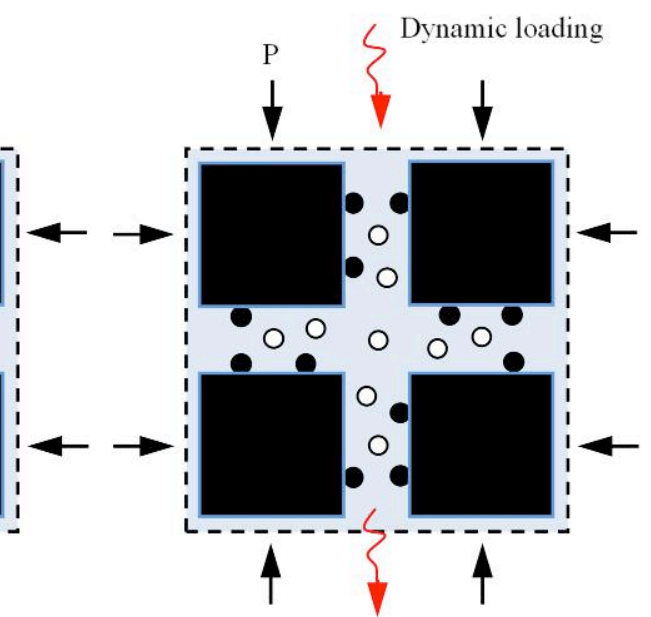

(c)

Fig. 10. Schematic of pore deformation of gas-containing coal. (a) Initial state. (b) Static loading. (c) Dynamic loading (P-gas pressure)

\section{Conclusions}

In this study, the experimental method of gas-containing coal was introduced to investigate the mechanical properties of gas-containing coal under static and dynamic loading. In addition, the static and dynamic compressive strengths of gas-containing coal were investigated using the selfdeveloped gas-sealing device and the modified SHPB equipment, respectively. Based on the experimental results, the failure model of gas-containing coal under various loading modes was analyzed. The following conclusions could be drawn:

(1) The state of the gas-saturated adsorption of the specimen prior to static loading could be identified using the self-developed gas-sealing device. In the static loading experiment, the static compressive strength and failure strain decreased with the increase of gas pressure.

(2) The improved SHPB could satisfy the requirements for the state of the gas-saturated adsorption prior to dynamic loading. In the experiment, the dynamic force on both sides of the specimen was balanced. As the gas pressure increased, the dynamic strength of the gas-containing coal decreased, whereas the dynamic failure strain increased.

(3) The results of DIF and GIF analyses showed that with the increase of initial gas pressure, DIF gradually increased and GIF remarkably decreased. The results also indicated that long-term loading contributed to the full desorption of adsorbed gas and promoted the crack propagation.

In this study, mechanical experiments under static and dynamic loading conditions are carried out respectively, and the loading mode is a little different from that in the mining field. The effect of the loading method that is nearly similar to the field conditions on the mechanical properties (such as pore deformation and gas adsorption state) of gas-containing coal will be further investigated for the additional comprehensive understanding of gas-containing coal.

\section{Acknowledgements}

The authors are grateful for the support provided by the National Natural Science Foundation of China (Grant Nos. 51774014 and 51304007), Anhui Provincial Natural Science Foundation (Grant Nos. 1808085ME159, 1808085QE149 and $1808085 \mathrm{ME} 134$ ) and the Natural Science Foundation of the Anhui Higher Education Institutions (Grant No. KJ2017A093).

This is an Open Access article distributed under the terms of the Creative Commons Attribution Licence

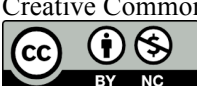

\section{References}

1. Xie, G. X., Hu, Z. X., Wang, L., "The coupling effect of the coal seam gas pressure and mining stress in working face". Journal of China Coal Society, 39(6), 2014, pp.1089-1093.

2. Li, C. W., Jie, B. J., Cao, G. L., Wang, T. T., Wang, X. Y., "The energy evaluation model of coal and gas outburst intensity". Journal of China Coal Society, 37(9), 2012, pp.1547-1552.

3. Wang, G., Wu, M., Wang, H., Huang, Q., Zhong, Y., "Sensitivity analysis of factors affecting coal and gas outburst based on a energy equilibrium model". Chinese Journal of Rock Mechanics and Engineering, 34(2), 2015, pp.238-248.

4. Pan, J., Ning, Y., Mao, D., Lan, H., Du, T., Peng, Y., "Theory of rockburst start-up during coal mining". Chinese Journal of Rock Mechanics and Engineering, 31(3), 2012, pp.586-596.
5. Dou, L., Jiang, Y., Cao, A., Liu, H., Gong, S., Cai, W., Zhu, G., "Monitoring and pre-warning of rockburst hazard with technology of stress field and wave field in underground coalmines". Chinese Journal of Rock Mechanics and Engineering, 36(4), 2017, pp.803811.

6. Alexeev, A. D., Revva, V. N., Alyshev, N. A., Zhitlyonok, D. M., "True triaxial loading apparatus and its application to coal outburst prediction". International Journal of Coal Geology, 58(4), 2004, pp. $245-250$.

7. Yin, Z. Q., Xie, G. X., Wang, L., Hu, Z. X., Zou, Y., "Acoustic emission characteristics of gas-containing coal during loading dilation process". Journal of Engineering Science and Technology Review, 8(5), 2015, pp.95-101. 
Yin Zhiqiang, Zhang Zhuo, Ma Haifeng, Hu Zuxiang and Tang Mingyun/

Journal of Engineering Science and Technology Review 11 (4) (2018) 61 - 68

8. He, M. C., Wang, C. G., Feng, J. L., Li, D. J., Zhang, G. Y. "Experimental investigations on gas desorption and transport in stressed coal under isothermal conditions". International Journal of Coal Geology, 83(4), 2010, pp.377-386.

9. Ranjith, P. G., Jasinge, D., Choi, S. K., Mehic, M., Shannon, B., "The effect of $\mathrm{CO} 2$ saturation on mechanical properties of Australian black coal using acoustic emission". Fuel, 89(8), 2010, pp.2110-2117.

10. Xie, G., Yin, Z., Wang, L., Hu, Z., Zhu, C., "Effects of gas pressure on the failure characteristics of coal". Rock Mechanics and Rock Engineering, 50(7), 2017, pp.1711-1723.

11. Xu, J., Feng, D., Cheng, L. C., Zhang, X. M., Tan, H. Y., Liu, J., "Mesoscopic evolution of coal containing gas's shear fracture". Journal of China Coal Society, 39(11), 2014, pp.2213-2219.

12. Yin, Z., Xie, G., Hu, Z., Zhu, C., "Investigation on fracture mechanism of coal rock on three-point bending tests under different gas pressures". Journal of China Coal Society, 41(2), 2016, pp.424431

13. Shan, R., Cheng, R., Gao, W., "Study on dynamic constitutive model of anthracite of Yunjialing coal mine". Chinese Journal of Rock Mechanics and Engineering, 25(11), 2006, pp.2258-2263.

14. Zhao, Y., Liu, S., Jiang, Y., Wang, K., Huang, Y., "Dynamic tensile strength of coal under dry and saturated conditions". Rock Mechanics and Rock Engineering, 49(5), 2016, pp.1709-1720.

15. Tao, M., Zhao, H. Li, X., Li, X., Du, K., "Failure characteristics and stress distribution of pre-stressed rock specimen with circular cavity subjected to dynamic loading". Tunnelling and Underground Space Technology, 81, 2018, pp.1-15.

16. Gong, F. Q., Luo, Y., Li, X. B., Si, X. F., Tao, M., "Experimental simulation investigation on rockburst induced by spalling failure in deep circular tunnels". Tunnelling and Underground Space Technology, 81, 2018, pp.413-427.
17. Li, X., Zhou, Z., Lok, T. S., Hong, L., Yin, T. "Innovative testing technique of rock subjected to coupled static and dynamic loads". International Journal of Rock Mechanics and Mining Sciences, 45(5), 2008, pp.739-748.

18. Yin, T., Wang, P., Li, X., Wu, B., Tao, M., Shu, R., "Determination of dynamic flexural tensile strength of thermally treated laurentian granite using semi-circular specimens". Rock Mechanics and Rock Engineering, 49(10), 2016, pp.3887-3898.

19. Li, D., Li, C. C., Li, X., "Influence of sample height-to-width ratios on failure mode for rectangular prism samples of hard rock loaded in uniaxial compression". Rock Mechanics and Rock Engineering, 44(3), 2011, pp.253-267.

20. Yin, Z. Q., Ma, H.F., Hu, Z. X., Zou, Y., "Effect of Static-Dynamic Coupling Loading on Fracture Toughness and Failure Characteristics in Marble". Journal of Engineering Science and Technology Review, 7(2), 2014, pp.169-174.

21. Tao, M., Ma, A., Cao, W., Li, X., Gong, F., "Dynamic response of pre-stressed rock with a circular cavity subject to transient loading". International Journal of Rock Mechanics and Mining Sciences, 99, 2017, pp.1-8.

22. Zhang, Q. B., Zhao, J., "Quasi-static and dynamic fracture behaviour of rock materials: phenomena and mechanisms". International Journal of Fracture, 189(1), 2014, pp.1-32.

23. Hao, Y., Hao, H., Zhang, X. H., "Numerical analysis of concrete material properties at high strain rate under direct tension". International Journal of Impact Engineering, 39(1), 2012, pp.5162.

24. Wang, C., Chen, W., Hao, H., Zhang, S., Song, R., Wang, X., "Experimental investigations of dynamic compressive properties of roller compacted concrete (RCC)". Construction and Building Materials, 168, 2018, pp.671-682.

25. Li, X., Li, Z., Wang, E., Feng, J., Kong, X., Chen, L., Li, B., Li, N., "Analysis of natural mineral earthquake and blast based on HilbertHuang transform (HHT)". Journal of Applied Geophysics, 128, 2016, pp.79-86. 